\title{
Hubungan Usia Menarche Dengan Usia Menopause Pada Wanita Menopause Di Wilayah Kerja Puskesmas Payung Sekaki
}

\author{
Eka Maya Saputri, SST, M.Kes ${ }^{(1)}$, Berliana Irianti, S.Si.T, M.Keb ${ }^{(2)}$ Putri Marisa ${ }^{(3)}$ \\ Email : ekamaya@htp.ac.id
}

\begin{abstract}
ABSTRAK
Menopause adalah fase terakhir, dimana perdarahan haid seorang wanita berhenti sama sekali. Fase ini terjadi berangsur-angsur yang semakin hari semakin jelas penurunan fungsi kelenjar indung telur (ovarium). Menopause terjadi pada usia yang bervariatif, rata-rata usia menopause 45-50 tahun dan pada dewasa ini ada kecendrungan untuk terjadinya menopause pada umur yang lebih tua. Tujuan penelitian ini adalah untuk mengetahui hubungan usia Menarche dengan Usia Menopause Pada Wanita Menopause di Wilayah Kerja puskesmas Payung Sekaki Tahun 2018. Penelitian ini dilaksanakan bulan September tahun 2018 di Puskesmas Payung Sekaki dengan menggunakan data primer dan populasinya adalah ibu menopause dipuskesmas Payung Sekaki Tahun 2018 dengan sampel sebanyak 98 orang ibu menopause. Teknik pengambilan sampel yaitu Accidental Sampling. Kemudian data dianalisis secara univariat dan bivariat. Instrumen penelitian ini menggunakan lembar observasi, dan diolah dengan menggunakan SPSS. Hasil penelitian diketahui bahwa dari 98 responden, 27 responden $(27,6 \%)$, diantaranya mengalami menarche dini, 50 responden $(51,0 \%)$ mengalami menarche Normal dan 21 responden $(21,4 \%)$ mengalami menarche Terlambat, usia menopause prematur sebanyak 3 responden $(3,1 \%)$, menopause normal 74 sampel $(75,5 \%)$, dan menopause terlambat 21 sampel $(21,4 \%)$ dengan P-value $>0,05$ yang berarti tidak ada hubungan yang bermakna antara usia menarche dengan usia menopause. Berdasarkan hasil penelitian diatas diharapkan agar lebih ditingkatkan sosialisasi tentang faktor-faktor yang dapat mempengaruhi menopause pada seorang wanita kepada seluruh penduduk wanita, baik melalui konseling ataupun penyuluhan.
\end{abstract}

\section{Kata Kunci : Menupause, Menarche}




\section{PENDAHULUAN}

Menurut siklus kehidupan wanita normal, setiap orang yang berusia panjang akan mengalami proses mulai dari bayi, masa kanak-kanak, remaja dewasa dan tua. Sehubungan dengan hal itu, kehidupan wanita juga mengalami fase-fase perkembangan tersebut. Dalam hal ini fase-fase yang berkaitan dengan fungsi organ reproduksi wanita. Fase ini meliputi prapubertas (sejak lahir hingga anak-anak) fase pubertas (remaja) fase reproduksi, fase perimenopause, fase menopause dan fase senium. Pada setiap fase, wanita mengalami perubahan yang penting pada alat kandungannya, baik perubahan anatomik maupun fisiologik.

Menopause merupakan akhir proses biologis dari siklus menstrusasi, yang dikarenakan terjadinya perubahan hormon yaitu penurunan produksi hormon estrogen yang dihasilkan oleh ovarium. Adanya penurunan hormon esterogen, hal ini menyebabkan siklus menstruasi menjadi tidak teratur, hal ini juga dapat dijadikan sebagai petunjuk terjadinya menopause.

Menopause terjadi pada usia yang bervariatif, rata-rata usia menopause 45-50 tahun dan pada dewasa ini ada kecendrungan untuk terjadinya menopause pada umur yang lebih tua (Sibagariang dkk, 2010) dan menurut Mulyani (2013) juga berpendapat bahwa ratarata usia menopause 49-51 tahun.

Pada masa menopause wanita akan mengalami perubahan-perubahan. Perubahan yang dirasakan yaitu, perubahan pola menstruasi, rasa panas (hot flush),keluar keringat dimalam hari, susah tidur, kerutan pada vagina, gejala gangguan motorik, gangguan psikis dan emosi, penurunan libido, depresi (Mulyani, 2013).

Menopause ternyata ada hubungan dengan pertama kali wanita mengalami haid (menarche). Menarche adalah haid yang pertama kali, biasanya terjadi pada usia 11 - 16 tahun yang merupakan peristiwa terpenting pada gadis remaja (Eva 2010). Semakin muda seorang wanita mengalami haid pertama sekali, semakin tua atau lama dia memasuki masa menopause dapat di artikan bahwa wanita yang mendapatkan menstruasi pada usia 16 atau 17 tahun akan mengalami menopause lebih dini, sedangkan untuk wanita yang haid lebih dini sering kali akan mengalami menopause sampai pada usia mencapai 50 tahun. (Mulyani, 2013)

\section{METODE KEGIATAN}

Penelitian ini bersifat kuantitatif menggunakan desain analitik yaitu untuk mengetahui hubungan antara usia menarche dengan usia menopause di wilayah kerja Puskesmas Payung Sekaki dengan pendekatan Cross Sectional.

\section{HASIL DAN PEMBAHASAN}

\section{Hasil Penelitian}

\section{a. Analisis Univariat}

Analisis univariat (analisis satu variabel) dilakukan pada setiap kategori jawaban pada variabel independen dan dependen 
yang ditampilkan dalam bentuk distribusi frekuensi. Analisis ini dilakukan untuk mendapatkan gambaran distribusi frekuensi usia menarche dengan usia menopause di Wilayah kerja Puskesmas Payung Sekaki Tahun 2018.

\section{Data Umum}

\section{a) Pendidikan}

\section{Tabel 4.1}

Distribusi Frekuensi pendidikan ibu menopause di Wilayah kerjaPuskesmas

Payung Sekaki Tahun 2018

\begin{tabular}{cccc}
\hline No & $\begin{array}{c}\text { Pendidikan } \\
\text { Ibu }\end{array}$ & $\begin{array}{c}\text { Frekuensi } \\
(\mathbf{f})\end{array}$ & $\begin{array}{c}\text { Presentasi } \\
(\mathbf{\%})\end{array}$ \\
\hline 1 & Tidak sekolah & 1 & $1,0 \%$ \\
\hline 2 & SD & 26 & $26,5 \%$ \\
\hline 3 & SMP & 41 & $41,8 \%$ \\
\hline 4 & SMA & 23 & $23,5 \%$ \\
\hline 5 & $\begin{array}{c}\text { Perguruan } \\
\text { Tinggi }\end{array}$ & 7 & $7,1 \%$ \\
\hline & Jumlah & 98 & $100 \%$ \\
\hline
\end{tabular}

Sumber : Data Primer 2018

Berdasarkan tabel 4.1 didapatkan hasil dari penelitian yang telah dilakukan dari 98 sampel dapat dilihat distribusi frekuensi pendidikan ibu menopause yang berpendidikan SMP yaitu 41 orang $(41,8 \%)$, dan Tidak sekolah 1 orang $(1,0 \%)$.

b) Pekerjaan

Tabel 4.2

Distribusi Frekuensi Pekerjaan Ibu Menopause di Wilayah Kerja Puskesmas Payung Sekaki Tahun 2018

\begin{tabular}{|c|c|c|c|}
\hline No & Pekerjaan Ibu & (f) & $(\%)$ \\
\hline 1 & IRT & 80 & $81,6 \%$ \\
\hline 2 & Wiraswasta & 13 & $13,3 \%$ \\
\hline 3 & PNS & 3 & $3,1 \%$ \\
\hline \multirow[t]{2}{*}{4} & Pensiunan & 2 & $2,0 \%$ \\
\hline & Jumlah & 98 & $100 \%$ \\
\hline
\end{tabular}

Berdasarkan tabel 4.2 didapatkan hasil dari 98 sampel dapat dilihat frekuensi pekerjaan ibu sebagai IRT sebanyak 80 orang $(81,6 \%)$, dan Pensiunan 2 orang $(2,0 \%)$

c) Alat Kontrasepsi yang pernah dipakai

Tabel 4.3

Distribusi frekuensi alat kontrasepsi yang pernah dipakai ibu menopause di Wilayah Kerja Puskesmas Payung Sekaki Tahun 2018

\begin{tabular}{llcc}
\hline No & $\begin{array}{c}\text { Alat kontrasepsi } \\
\text { yang pernah } \\
\text { dipakai }\end{array}$ & $\begin{array}{c}\text { Frekuensi } \\
\text { (f) }\end{array}$ & $\begin{array}{c}\text { Presentasi } \\
(\%)\end{array}$ \\
\hline 1 & Hormonal & 81 & $82,7 \%$ \\
\hline 2 & Non Hormonal & 17 & $17,3 \%$ \\
\hline & Jumlah & 98 & $100 \%$ \\
\hline \multicolumn{3}{c}{ Sumber : Data Primer 2018 }
\end{tabular}

Berdasarkan tabel 4.3 didapatkan hasil dari 98 responden, distribusi frekuensi alat kontrasepsi yang pernah dipakai ibu Hormonal sebanyak 81 orang $(82,7 \%)$, Non Hormonal 17 orang $(17,3 \%)$.

d) Usia melahirkan anak terakhir

Tabel 4.4

Distribusi frekuensi Usia melahirkan anak terakhir ibu menopause di Wilayah Kerja Puskesmas Payung Sekaki Tahun 2018

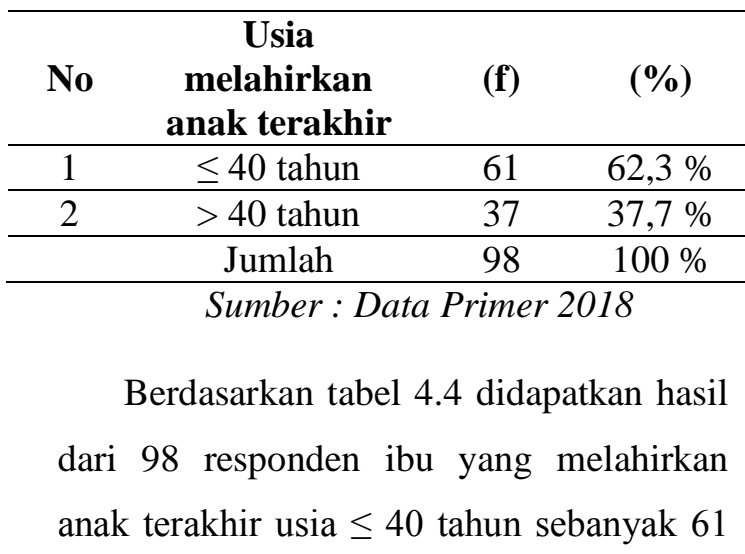


orang $(62,3 \%)$, usia $>40$ tahun 37 orang $(37,7 \%)$

\section{Data Khusus}

a) Usia Menarche

Tabel 4.5

Distribusi frekuensi usia menarche ibu menopause di Wilayah Kerja Puskesmas Payung Sekaki Tahun 2018

\begin{tabular}{|c|c|c|c|}
\hline No & $\begin{array}{c}\text { Usia } \\
\text { Menarche }\end{array}$ & $\begin{array}{l}\text { Frekuensi } \\
\text { (f) }\end{array}$ & $\begin{array}{c}\text { Presentasi } \\
(\%)\end{array}$ \\
\hline 1 & $\begin{array}{l}\text { Dini }(<12 \\
\text { tahun })\end{array}$ & 27 & $27,6 \%$ \\
\hline 2 & $\begin{array}{l}\text { Normal (12- } \\
14 \text { tahun) }\end{array}$ & 50 & $51,0 \%$ \\
\hline \multirow[t]{2}{*}{3} & $\begin{array}{c}\text { Terlambat (> } \\
14 \text { tahun) }\end{array}$ & 21 & $21,4 \%$ \\
\hline & Jumlah & 98 & $100 \%$ \\
\hline
\end{tabular}

Berdasarkan tabel 4.5 didapatkan hasil dari 98 responden usia menarche dini $(<12$ tahun) sebanyak 27 orang $(27,6 \%)$, menarche Normal (12-14 tahun) 50 orang (51,0\%), menarche Terlambat (> 14 tahun) 21 orang $(21,4 \%)$.

\section{b) Usia Menopause}

Tabel 4.6

Distribusi Frekuensi usia menopause diwilayah kerja Puskesmas Payung Sekaki Tahun 2018

\begin{tabular}{cccc}
\hline No & $\begin{array}{c}\text { Usia } \\
\text { Menopause }\end{array}$ & $\begin{array}{c}\text { Frekuensi } \\
(\mathbf{f})\end{array}$ & $\begin{array}{c}\text { Presentasi } \\
(\mathbf{\%})\end{array}$ \\
\hline 1 & $\begin{array}{c}\text { Prematur } \\
(<40 \text { tahun })\end{array}$ & 3 & $3,1 \%$ \\
\hline 2 & $\begin{array}{c}\text { Normal } \\
(40-50 \\
\text { tahun })\end{array}$ & 74 & $75,5 \%$ \\
\hline 3 & $\begin{array}{c}\text { Terlambat } \\
(>51 \text { tahun })\end{array}$ & 21 & $21,4 \%$ \\
\hline & Jumlah & 98 & $100 \%$ \\
\hline
\end{tabular}

Sumber : Data Primer 2018
Berdasarkan tabel 4.6 didapatkan hasil penelitian dari 98 sampel menopause prematur $(<40$ tahun) sebanyak 3 orang $(3,1$ $\%$ ), menopause normal (40-50 tahun) 74 orang $(75,5 \%)$, menopause Terlambat ( $>51$ tahun) 21 orang $(21,4 \%)$.

\section{b. Analisis Bivariat}

Data Bivariat ini dilakukan untuk mengetahui hubungan antara variable independen dengan variabel dependen dengan cara menggunakan program SPSS yaitu: Hubungan Usia Menarche Dengan Usia Menopause pada Wanita Menopause di Wilayah Kerja Puskesmas Payung Sekaki Tahun 2018.

Tabel 4.7

Hubungan Usia Menarche Dengan Usia Menopause pada Wanita Menopause di Wilayah KerjaPuskesmas Payung Sekaki Tahun 2018

\begin{tabular}{|c|c|c|c|c|c|c|c|c|c|}
\hline $\begin{array}{l}\text { Men } \\
\text { opdy } \\
\text { se }\end{array}$ & Pre & atur & & rmal & & $\begin{array}{l}\text { lam } \\
\text { at }\end{array}$ & & D & \\
\hline $\begin{array}{l}\text { Men } \\
\text { arch } \\
\text { e }\end{array}$ & $\mathrm{N}$ & \% & $\mathrm{N}$ & $\%$ & $\mathrm{~N}$ & $\%$ & $\mathrm{~N}$ & $\begin{array}{l}\text { Vall } \\
\mathrm{e}\end{array}$ & $\alpha$ \\
\hline Dini & 2 & $7,4 \%$ & $\begin{array}{l}1 \\
7\end{array}$ & $\begin{array}{c}63,0 \\
\%\end{array}$ & 8 & $\begin{array}{l}29, \\
6 \%\end{array}$ & $\begin{array}{l}2 \\
7\end{array}$ & & \\
\hline $\begin{array}{l}\text { Nor } \\
\text { mal }\end{array}$ & 0 & $0 \%$ & $\begin{array}{l}4 \\
0\end{array}$ & $\begin{array}{c}80,0 \\
\%\end{array}$ & $\begin{array}{l}1 \\
0\end{array}$ & $\begin{array}{l}20 \\
0 \%\end{array}$ & $\begin{array}{l}5 \\
0\end{array}$ & $\begin{array}{l}0 . \\
2\end{array}$ & 0. \\
\hline $\begin{array}{l}\text { Terla } \\
\text { mbat }\end{array}$ & 1 & $4,8 \%$ & $\begin{array}{l}1 \\
7\end{array}$ & $\begin{array}{c}81,0 \\
\%\end{array}$ & 3 & $\begin{array}{l}14, \\
3 \%\end{array}$ & $\begin{array}{l}2 \\
1\end{array}$ & $\begin{array}{l}3 \\
4\end{array}$ & \\
\hline $\mathrm{N}$ & 3 & $3,1 \%$ & $\begin{array}{l}7 \\
4\end{array}$ & $\begin{array}{c}75,5 \\
\%\end{array}$ & $\begin{array}{l}2 \\
1\end{array}$ & $\begin{array}{l}21 \\
4 \%\end{array}$ & $\begin{array}{l}9 \\
8\end{array}$ & & \\
\hline
\end{tabular}


Berdasarkan tabel 4.7 tingginya presentasi menopause normal terdapat pada menarche terlambat dengan jumlah $81,0 \%$. Dari hasil analisis uji chi square maka didapatkan hasil bahwa P-Value $>\alpha(0,234>0,05)$ maka Ha ditolak, sehingga tidak ada hubungan yang signifikan antara usia menarche dengan usia menopause

\section{Pembahasan}

Dari hasil penelitian telah diperoleh data yang dapat dijadikan ataupun tolak ukur dalam melakukan pembahasan dan sebagai hasil akhir dapat dinyatakan sebagai berikut :

\section{a. Usia Menarche}

Hasil penelitian dari tabel 4.5 menunjukkan bahwa dari 98 responden, mayoritas usia menarche di Wilayah Kerja Puskesmas Payung Sekaki normal sebanyak 50 orang $(51,02 \%)$.

Menarche adalah perdarahan pertama kali dari uterus yang terjadi pada wanita di masa pubertas sekitar usia 12-14 tahun. Menarche merupakan perubahan yang menandakan bahwa remaja sudah memasuki tahap kematangan organ seksual. Menarchedimulai dari pertumbuhan organ seks sekunder tumbuh berkembang, seperti pembesaran payudara, tumbuh rambut ketiak, panggul membesar serta mulai berkembangnya beberapa organ vital yang siap untuk dibuahi (Manuaba, 2009).

Gejala yang sering menyertai menarche adalah rasa tidak nyaman disebabkan karena selama menstruasi volume air didalam tubuh berkurang. Gejala lain yang dirasakan yaitu sakit kepala, pegal-pegal dikaki dan dipinggang untuk beberapa jam, kram perut dan sakit perut. Sebelum periode ini terjadi biasanya ada beberapa perubahan emosional. Perasaan suntuk, marah dan sedih yang disebabkan oleh adanya pelepasan beberapa hormon (Proverawati, 2009).

Terjadinya menarche dipengaruhi oleh beberapa faktor yang diduga berhubungan dengan faktor endogen yaitu genetik dan faktor eksogen, yaitu status sosial ekonomi keluarga, status gizi, keadaan keluarga, tempat tinggal kegiatan fisik dan keterpaparan terhadap media massa orang dewasa (Ginarhayu, 2002).

\section{b. Usia Menopause}

Dari tabel 4.6 hasil penelitian menunjukkan bahwa dari 98 responden usia menopause di Wilayah Kerja Puskesmas Payung Sekaki mayoritas normal 74 orang $(75,51 \%)$.

Menopause adalah haid terakhir yang dialami oleh seorang wanita yang masih dipengaruhi oleh hormon reproduksi yang terjadi pada usia menjelang atau pada usia lima puluhan (Fitrah, 2010).

Wanita menopause akan kekurangan hormon utamanya hormon estrogen sehingga timbul beberapa gejala seperti rasa panas di beberapa bagian tubuh dipaha dan kaki, perasaan sakit ketika melakukan hubungan seks dan berkurangnya kepadatan tulang, kelainan tersebut dapat ditolong dengan pemberian estrogen (Mulyani, 2013).

Menurut Wahyuni (2010), upaya untuk mengurangi keluhan menopause diantaranya yaitu pemberian obat yang bersifat menggantikan fungsi hormon estrogen, 
mengkonsumsi vitamin, olahraga yang cukup, makan dengan menu seimbang dan sesuai kebutuhan, dan berkonsultasi dengan orang yang pakar dalam masalah menopause.

Berdasarkan hasil penelitian yang dilakukan, Peneliti berasumsi bahwa usia menopause normal. Disebabkan karena ibu yang memakai kontrasepsi hormonal. Dari 98 responden 81 orang $(82,7 \%)$ menggunakan kontrasepsi hormonal dan 17 orang (17,3\%) menggunakan kontrasepsi non hormonal Hal ini dikarenakan cara kerja kontrasepsi yang menekan kerja ovarium atau indung telur. Pada wanita yang menggunakan alat kontrasepsi hormonal akan lebih lama atau lebih tua memasuki masa menopause.

\section{c. Hubungan Usia Menarche dengan Usia Menopause pada Wanita Menopause di Wilayah Kerja Puskesmas Payung Sekaki Tahun 2018}

Berdasarkan hasil uji analisis didapatkan P-Value $>\alpha(0,234>0,05)$, maka Ha ditolak, sehingga disimpulkan tidak ada hubungan yang signifikan antara usia menarche dengan usia menopause.

Menurut Mulyani (2013), terjadinya menopause ada hubungannya dengan pertama kali wanita mengalami haid (menarche). Semakin muda seorang wanita mengalami haid pertama sekali, semakin tua atau lama dia memasuki masa menopause dapat di artikan bahwa wanita yang mendapatkan menstruasi pada usia 16 atau 17 tahun akan mengalami menopause lebih dini, sedangkan untuk wanita yang haid lebih dini sering kali akan mengalami menopause sampai pada usia mencapai 50 tahun.

$$
\text { Menurut Prawiroharjo (2005), }
$$

menopause ada hubungannya dengan menarche dimana makin dini menarche terjadi, maka makin lambat menopause muncul sebaliknya makin lambat menarche terjadi, makin cepat menopause muncul. Pada abad ini umumnya terlihat bahwa menarche makin dini timbul dan menopause makin lambat terjadi, sehingga masa reproduksi menjadi panjang.

Peneliti berpendapat bahwa usia menarche tidak mempengaruhi terjadinya menopause, karena dari 98 responden didapatkan tingginya presentasi menarche terlambat terdapat pada menopause normal dengan jumlah $81,0 \%$. Hal ini dapat terjadi karena adanya faktor-faktor lain selain usia menarche yang dapat mempengaruhi terjadinya usia menopause menjadi lebih dini atau lambat.

Adapun faktor tersebut yaitu paritas, secara biologis, wanita yang memiliki paritas yang tinggi (>3), jumlah kumulatif siklus menstruasinya akan lebih rendah di bandingkan dengan wanita yang tidak memiliki anak. Hal tersebut berpengaruh terhadap cadangan ovarium yang lebih banyak dan paparan hormon estrogen menjadi lebih lama sehingga wanita yang memiliki paritas yang tinggi cenderung akan mengalami menopause pada usia yang lebih lambat (Kasdu dalam Anindita, 2015). Hal ini berbeda dengan peneliti lakukan dimana ditemukan wanita yang mengalami paritas tinggi 50 orang $(51,0 \%)$. 
Selain itu, Status Perkawinan, keadaan seorang wanita yang tidak menikah diduga mempengaruhi perkembangan reproduksinya. Mereka akan mengalami masa menopause lebih muda atau lebih cepat dibandingkan dengan wanita yang telah menikah. Wanita menikah cenderung lebih aktif melakukan aktivitas seksual dibandingkan wanita yang tidak menikah. Wanita yang aktif secara seksual setidaknya sekali seminggu menunjukkan tingkat estrogen yang lebih tinggi dibandingkan dengan wanita kurang aktif secara seksual (Kasdu dalam Anindita, 2015).

Usia Melahirkan, wanita yang masih melahirkan diatas 40 tahun akan mengalami usia menopausen yang lebih tua, semakin tua seseorang melahirkan anak, semakin tua ia mulai memasuki usia menopause. Hal ini terjadi karena kehamilan dan persalinan akan memperlambat sistem kerja organ reproduksi. Bahkan akan memperlambat proses penuaan dini (Kasdu dalam Anindita, 2015). Hal ini berbeda dengan peneliti lakukan dimana di temukan usia terakhir kali responden yang masih melahirkan diatas 40 tahun 37 0rang $(37,7 \%)$

\section{KESIMPULAN}

Berdasarkan analisis data hasil penelitian dan pembahasan mengenai hubungan usia menarche dengan usia menopause pada wanita menopause di Wilayah Kerja Puskesmas Payung Sekaki Tahun 2018 yaiutu Tidak ada hubungan Usia Menarche dengan Usia Menopause pada wanita menopause di Wilayah Kerja
Puskesmas Payung Sekaki Tahun 2017 dengan

P-Value $>\alpha(0,234>0,05)$.

\section{DAFTAR PUSTAKA}

Arikunto, S.( 2006). Prosedur penelitian dan pendekatan praktek. Jakarta : Rineka Cipta

Baziad, A.( 2008). Endokrinologi Ginekologi. Jakarta : media aesculapius fakultas kedokteran universitas indonesia.

Hidayat, A. A. (2007). Metode penelitian kebidanan dan teknik analisa data. Jakarta : salemba Medika

Indarti. 2004. Panduan Kesehatan Wanita. Jakarta.

Kartono, K. 2002, Psikologi Wanita I, Mengenal Gadis Remaja dan Wanita Dewasa. Bandung : Mandar Maju, Bandung.

Kasdu, Dini. 2004. Solusi Problem Wanita Dewasa Cet. I. Jakarta : Puspa Swara

Mulyani N. 2013. Akhir Siklus Menstruasi Pada Wanita Diusia Pertengahan. Yogyakarta : Nuha Medika

Munawaroh N. 2010. Hubungan Antara Usia Menarche Dengan Usia Menopause Pada Ibu-Ibu Pasca Menopause Didesa Bumi Rejo Lendah Kulon Progo Yogyakarta. http://opac.unisayogya.ac.id/1777/1/N ASPUB.pdf Diakses 17 september pukul 13: 36

Notoadmojo. 2010. Metode penelitian kesehatan, Rineka Cipta : Jakarta.

Prawiroharjo S. 2011. Ilmu Kandungan. Jakarta : PT. Bina Pustaka Sarwono Prawirohardjo.

Prawirohardjo S. 2007. Ilmu Kandungan. Jakarta : Tridasa Printer.

Proverawati, A \& Misaroh, S. 2009. Menarche. Yogyakarta: Nuha Medika.

Senolinggi, dkk. 2014. Hubungan Antara Usia Menarche Dengan Usia Menopause Pada Wanita Di Kecamatan Kakas Sulawesi Utara Tahun 2014 http://ejournal.unsrat.ac.id/index.php/ eclinic/article/viewFile/6754/6278. Diakses 19 agustus pukul 13:19

Setiadi. 2007. Konsep dan Penulisan Riset Keperawatan. Surabaya : Graha Ilmu.

Sulistyaningsih. 2011. Metodologi Penelitian Kebidanan Kuantitatif Kualitatif. Edisi I. Yogyakarta. Penerbit Graha Ilmu. 
Wahyuni 2010. Memahami Kesehatan Pada Lansa. Jakarta : Trans Info Medika.

Waryana. 2010. Gizi Reproduksi. Yogyakarta : Pustaka Rihama.

Wiknjosastro, Hanif. 2005. Ilmu Kandungan. Jakarta - SP
Yatim, Faisal. 2001. Haid Tidak Wajar dan Menopause. Jakarta : Pustaka Populer Obor. 